\title{
A Specialized Transducing Phage, $\lambda$ psrlA, for the Sorbitol Phosphotransferase of Escherichia coli K 12
}

\author{
By A. BORONAT, M. C. JONES-MORTIMER* AND H. L. KORNBERG \\ Department of Biochemistry, University of Cambridge, Tennis Court Road, \\ Cambridge CB2 $1 Q W$, U.K.
}

(Received 7 July 1981)

\begin{abstract}
A specialized transducing phage for the $\operatorname{srlA}$ gene, specifying the sorbitol-specific Enzyme II of the phosphoenolpyruvate: sugar phosphotransferase system, was constructed and its DNA was analysed by restriction endonuclease digestion. Phage construction involved four steps: (1) integration of $\lambda$ into the srlA gene; (2) selection of phage carrying (a) the left and (b) the right end of the $s r l A$ gene by means independent of the function of the new DNA acquired; (3) reconstitution of the $\operatorname{srlA}$ gene in a dilysogen of these two phage; and (4) the excision, using the heteroimmune lambdoid phage 21 , of a plaque-forming $\mathrm{srlA}^{+}$phage from the dilysogenic chromosome. Comparison of the DNA restriction digests of the transducing phage with those of its parents and of wild-type $\lambda$ revealed fragments consisting partly of $\lambda$ and partly of Escherichia coli DNA. The junction points in the intermediate phage define a site that must lie within the reconstituted gene of the final phage. This technique should be of general application in relating genes, cloned by our method, to DNA sequences.
\end{abstract}

\section{INTRODUCTION}

Most of the techniques described for the isolation of specialized transducing phage rely on the positioning of the gene to be cloned adjacent to an attachment site of a lambdoid phage (Morse et al., 1956; Beckwith et al., 1966; Press et al., 1971; Shimada et al., 1972). However, Davis \& Calvo (1977) and Mata et al. (1978) have obtained specialized transducing phage for genes into which $\lambda$ has integrated.

Because of our interest in the exclusion by glucose of other carbohydrates (Kornberg et al., 1980), we wished to investigate more closely one of the membrane-bound Enzymes II of the phosphoenolpyruvate-dependent sugar phosphotransferase system, since we believe (Amaral \& Kornberg, 1975) that these proteins are the sites at which catabolite inhibition (McGinnis $\&$ Paigen, 1969) may act. Since McEntee (1977) has shown that $\lambda$ will integrate into $\operatorname{srl} A$, the gene for the sorbitol Enzyme II, this appeared to be a suitable system for the production of specialized transducing phage.

\section{METHODS}

The Escherichia coli strains used are listed in Table 1; the phage strains are in Table 2. The general microbiological methods were those used previously (Jones-Mortimer \& Kornberg, 1976). $\lambda$ methods and media were those of Gottesman \& Yarmolinsky (1968 a) and Shimada et al. (1972).

$\lambda$ DNA was prepared by the rapid lysis technique of Davies et al. (1980). Digestions with EcoRI (BCL, London), HindIII, BamHI and KpnI (Bethesda Research Laboratories, Cambridge) were carried out in the buffers recommended by the manufacturers, using about $1 \mu \mathrm{g}$ DNA in a final volume of $50 \mu \mathrm{l}$. Double digestions were performed by digesting first with the enzyme requiring the lower ionic strength and subsequently adjusting for the conditions required for the second enzyme. After addition of $10 \mu \mathrm{l}$ of sample buffer $40 \mathrm{mM}-\mathrm{EDTA}, 0 \cdot 1 \%(\mathrm{w} / \mathrm{v})$ sodium dodecyl sulphate, $30 \%(\mathrm{w} / \mathrm{v})$ Ficoll, $0.25 \%(\mathrm{w} / \mathrm{v})$ bromophenol blue], samples were heated at $60^{\circ} \mathrm{C}$ for 


\section{Table 1. Strains of Escherichia coli used}

\begin{tabular}{|c|c|c|}
\hline Strain & Relevant genotype & Source or reference \\
\hline $\mathrm{CSH} 25$ & $\operatorname{tyr} T$ & P. Oliver \\
\hline $\mathrm{H} 50$ & $(\operatorname{srl} r e c A)^{\Delta} \mathrm{mtl}$ & P. Oliver \\
\hline JM759 & ton $A(\text { gal uvrB })^{\Delta}$ ptsF pts $M$ & Jones-Mortimer \& Kornberg (1976) \\
\hline JM 1099 & galK & Henderson et al. (1977) \\
\hline JM1521 & $\operatorname{ton} A^{+}(\text {gal uvrB })^{\Delta}$ ptsF ptsM srlC & JM759 \\
\hline JM1551 & $\operatorname{srlA}:: \lambda c 1857 S 7$ & J.1521 \\
\hline JM1554 & $\operatorname{srlA}:: \lambda c I 857 S 7 \lambda^{\mathrm{R}}$ & JM1551 \\
\hline JM 1684 & $(\lambda \mathrm{JM} 19)(\lambda \mathrm{JM} 20)$ & $\mathrm{H} 50$ \\
\hline JM 1700 & srlA tyrT $(21)$ & $*$ \\
\hline JM1710 & $(\operatorname{srl} r e c A)^{i} m t l\left(\lambda c^{+}\right)$ & $*$ \\
\hline JM1719 & $(\text { gal uvrB })^{\Delta}$ ptsF ptsM srlC $C^{+}$srlA & $*$ \\
\hline RB341 & $\operatorname{tyr} T(\mathrm{P} 2)$ & Buxton et al. (1978) \\
\hline $\mathrm{P} 4 \mathrm{X}$ & $\operatorname{ton} A^{+}$ & \\
\hline PO345 & srlmtl & P. Oliver \\
\hline
\end{tabular}

Table 2. Strains of bacteriophage used

\begin{tabular}{ll}
\multicolumn{1}{c}{ Strain } & \multicolumn{1}{c}{ Source } \\
$\lambda c I 857 S 7$ & P. Oliver \\
$\lambda c I b 2$ & P. Oliver \\
$\lambda c h 80$ del & P. Oliver \\
$\lambda \mathrm{JM} 19\left(\mathrm{Spi}^{-}\right)$ & E. coli JM 1554 \\
$\lambda \mathrm{JM} 20\left(\mathrm{EDTA}^{\mathrm{R}}\right)$ & E. coli $\mathrm{JM} 1554$ \\
$\lambda \mathrm{JM} 23\left(\operatorname{srl} / A^{+}\right)$ & E. coli JM 1684 \\
$\lambda \mathrm{JM} 24\left(\operatorname{srl} A^{+}\right)$ & E. coli JM 1684 \\
$\mathrm{P} 1 \mathrm{kc}$ & M. D. Yudkin \\
21 & P. Oliver
\end{tabular}

$5 \mathrm{~min}$ and applied to horizontal agarose gels $(0.5-1 \%, \mathrm{w} / \mathrm{v})$ containing $40 \mathrm{mM}$-Tris/acetate buffer, $\mathrm{pH} 7.7$, $1 \mathrm{mM}$-EDTA and $0.5 \mu \mathrm{g}$ ethidium bromide $\mathrm{ml}^{-1}$. Similar Tris/acetate/EDTA buffer was used in the electrode wells. Gels were run at $2-5 \mathrm{~V} \mathrm{~cm}^{-1}$ and photographed under short wavelength u.v. illumination. Digests of $\lambda c I 857 S 7$ DNA with EcoRI and HindIII were used as standards in all gels to relate mobility to fragment size, and as Fig. 3 indicates, all samples were internally calibrated.

\section{RES ULTS}

\section{Construction of $\lambda$ psrla ${ }^{+}$}

Strain JM1521 was obtained from strain JM759 (Jones-Mortimer \& Kornberg, 1976; Henderson et al., 1977) in two stages. Bacteriophage Plkc grown on strain P4X was used to transduce strain JM759 (tonA) to glucarate-positive phenotype (Roberton et al., 1980). A ton $A^{+}$recombinant from this cross was plated on fructose minimal medium at $30^{\circ} \mathrm{C}$ to select for a sorbitol constitutive ( $\operatorname{srlC}$ ) mutation (Jones-Mortimer \& Kornberg, 1976). Subsequent stages of the construction are outlined in Fig. 1. An srlC strain, JM1521, was lysogenized with $\lambda c I 857 S 7$ by the procedure of Shimada et al. (1972). After growth to allow phenotypic expression the cells were plated, together with $\lambda c I b 2$ and $\lambda$ ch80del9, on glycerol minimal medium containing 2-deoxy-2-amino-D-glucitol (10 mM). Under these conditions, only strains that are both lysogenic for $\lambda$ and lack the sorbitol phosphotransferase can grow, since the $\lambda$ strains kill any non-lysogens, and the 2-deoxy-2-amino-D-glucitol inhibits strains expressing sorbitol phosphotransferase activity (Jones-Mortimer \& Kornberg, 1976). One such lysogen, strain JM1551, was chosen, since it could grow on carbon sources other than sorbitol that require $p t s H$ and $p t s I$ activity and, on heat-pulse curing (Shimada et al., 1972), it regained the 

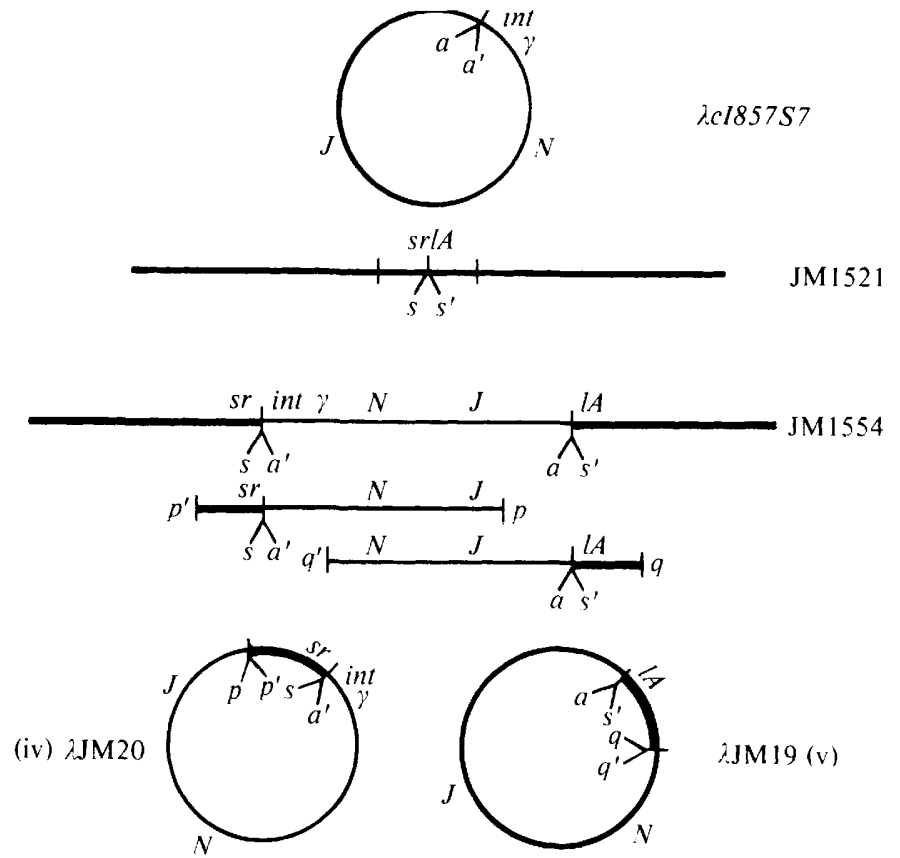

$2 J M 19$ (v)

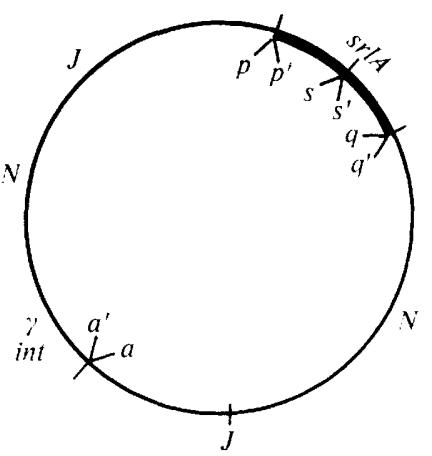

(vi)

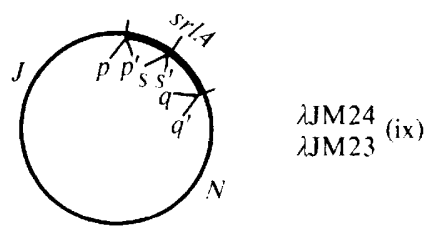

Fig. 1. Schematic representation of the construction of $\lambda$ psrlA: (i) wild-type $\lambda$; (ii) $s r l A^{+}$att $\lambda^{\Delta}$ host; (iii) lysogen with $\lambda$ integrated into $s r l A$; (jv) EDTA-resistant phage of the $\lambda$ pgal type; (v) Spi ${ }^{-}$phage of the $\lambda$ pbio type; (vi) hypothetical intermediate resulting from an int-xis -mediated recombination between structures (iv) and (v); (vii) $\operatorname{srl} A^{\Delta}$ att $\lambda^{+}$host: (viii) dilysogen with structure (vi) integrated at att $\lambda$; (ix) $\lambda$ psrlA, the product of Ter-mediated excision through $m$ and $m^{\prime}$.

$\lambda$ (i) was integrated into the $\operatorname{srlA}$ gene of the att $\lambda^{\Delta}$ host (ii) to yield the lysogen (iii). Induction and screening of the liberated phage yielded the phage (iv) and ( $v$ ) each of which carries part of the $s r l A$ gene. Simultaneous infection of a srlA-deletion strain (vii) with (iv) and (v) yielded the $\mathrm{Srl}^{+}$tandem dilysogen (viii) perhaps via the hypothetical intermediate (vi). The sorbitol transducing phage (ix) were obtained from the dilysogen by Ter-mediated excision using phage 21 . 
ability to grow with sorbitol as carbon source. From this strain a $\lambda^{\mathrm{R}}$ derivative strain JM1554 was isolated by selection for resistance to $\lambda$ vir.

Strain JM1554 was thermally induced. The cells were then concentrated 10 -fold by centrifugation and lysed by the addition of chloroform. After the removal of cell debris by centrifugation, portions of the supernatant fluid were plated on the P2 lysogen RB341. A Spi ${ }^{-}$ plaque, strain $\lambda \mathrm{JM} 19$ (Table 2), was purified for subsequent experiments. [Spi ${ }^{-} \lambda$ mutants have lost the red and gam genes and have acquired a recombinational hot-spot. Thus, when obtained from an induced lysate, they usually carry E. coli DNA (Lindahl et al., 1970).] Other portions of the supernatant fluid were treated with EDTA (Gottesman, cited in Buxton et al., 1978). A survivor of this treatment, strain $\lambda \mathrm{JM} 20$, was obtained as a plaque on $E$. coli strain CSH25. It was shown to be able to transduce the $\mathrm{Srl}^{-} E$. coli strain $\mathrm{PO} 345$ to $\mathrm{Srl}^{+}$.

The two $\lambda$ strains thus obtained were used to infect the $\operatorname{sr} l A$ rec $A$ deletion strain H50, and progeny were selected on sorbitol minimal medium. One of these strains, JM1684, was apparently a dilysogen carrying both $\lambda \mathrm{JM} 19$ and $\lambda \mathrm{JM} 20$ integrated at att $\lambda$ since it had the following properties: (1) non-lysogens obtained from it by heat-pulse curing were sorbitol-negative; (2) a thermally induced lysate transduced a galK strain (JM1099) to $\mathrm{Gal}^{+}$ at a frequency of $1 \times 10^{-7}$; (3) the lysate transduced strain $\mathrm{H} 50$ to $\mathrm{Srl}^{+}$.

A plot of the logarithm of the number of transductants obtained in this cross against the logarithm of the phage dilution employed had a slope of $-1 \cdot 2$, showing that many of the transductants must have arisen from infection by a single transducing particle. However, none of the transductants examined yielded plaque-forming transducing phage on induction; in contrast, such phage could be obtained from strain JM1684 by Ter-mediated excision (Gottesman \& Yarmolinsky, $1968 b$; Mousset \& Thomas, 1968). [In Ter-mediated excision the superinfecting phage mistakes the two tandem $\cos$ sites $\left(\mathrm{mm}^{\prime}\right.$ in Fig. 1) of the dilysogen for the equivalent sites in the replicative form of its own DNA and packages the DNA between these sites.]

Phage 21 , which has the same host range as $\lambda$ but differs from $\lambda$ in the specificity of its $\mathrm{N}$ protein and of its int and xis proteins as well as in its immunity, was propagated on strain JM1684 at $30^{\circ} \mathrm{C}$ in liquid culture. The lysate was plated at suitable dilutions on strain JM1700 [srlA tyrT (21)] on tetrazolium sorbitol medium at $30^{\circ} \mathrm{C}$. After incubation for $3 \mathrm{~d}$, about $1 \%$ of the plaques had pale pink edges which indicated that the unlysed but infected cells round the edges could utilize the sorbitol in the medium. Two phages of $\lambda$ immunity, $\lambda \mathrm{JM} 23$ and $\lambda \mathrm{JM} 24$, were isolated from one such plaque.

\section{Characterization of $\lambda$ psrlA ${ }^{+}$}

Biological characterization. Both $\lambda \mathrm{JM} 23$ and $\lambda \mathrm{JM} 24$ transduced strain $\mathrm{H} 50$ to $\mathrm{Srl}^{+}$with $\lambda c 1857 S 7$ as helper. That $\lambda \mathrm{JM} 23$ carried the complete $s r l A^{+}$gene was shown by infecting strain JM1710 $\left[(\operatorname{rec} A \operatorname{srl} A)^{\Delta}\left(\lambda^{+}\right)\right]$in liquid culture. The results of this experiment are shown in Fig. 2. Neither $\lambda J M 19$ nor $\lambda J M 20$ stimulated the growth of strain JM1710 on sorbitol. A mixture of the two phage preparations was equally ineffective. Nevertheless, infection with dJM23 allowed growth in the presence of sorbitol (but not in the absence of a carbon source). Since strain JM1710 is a recombination-deficient homoimmune lysogen, the $s r l A^{+}$gene on the superinfecting phage must be expressed.

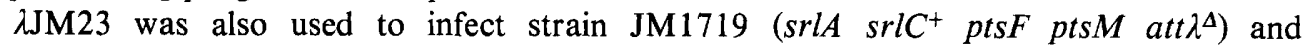
sorbitol-positive transductants were selected; these were fructose-negative and thermosensitive (but readily yielded fructose-positive derivatives): One such sorbitol-positive strain was streaked out for single colonies. Of 80 such colonies tested, 2 were found now to be sorbitol-negative and 2 were fructose-positive. We have previously shown (Jones-Mortimer \& Kornberg, 1976) that in appropriate strains fructose can be utilized by the sorbitol phosphotransferase, if that system is expressed constitutively; our results are therefore consistent with the segregation of haploids from a $\mathrm{srlA} \mathrm{srlC} \mathrm{C}^{+} / \lambda \mathrm{srlA} \mathrm{A}^{+} \mathrm{srlC}$ diploid if both $\mathrm{srlA} \mathrm{A}^{+}$ 


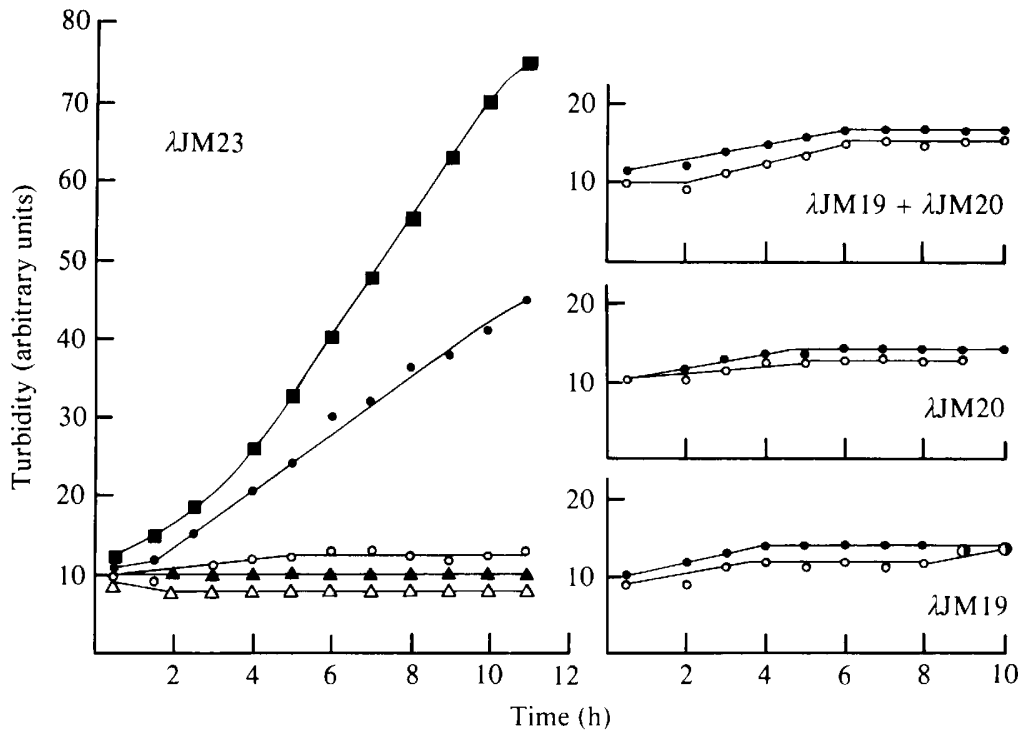

Fig. 2. Effect of $\lambda$ psrlA ( $\lambda \mathrm{JM} 23$ ) on sorbitol utilization by a sorbitol-negative strain. A maltose-grown culture of strain JM1710 [ $\left.(\operatorname{srlA} \text { rec } A)^{\boldsymbol{\Lambda}}\left(\lambda c^{+}\right)\right]$was incubated with maltose $(\boldsymbol{\square})$, sorbitol $(\mathbf{\Delta})$ or no carbon source $(\triangle)$, or infected with $\lambda \mathrm{JM} 23, \lambda \mathrm{JM} 19, \lambda \mathrm{JM} 20$ or a mixture of $\lambda \mathrm{JM} 19$ and $\lambda \mathrm{JM} 20$ and incubated with sorbitol (O) or no carbon source $(O)$. The increase in turbidity is shown as a function of time.

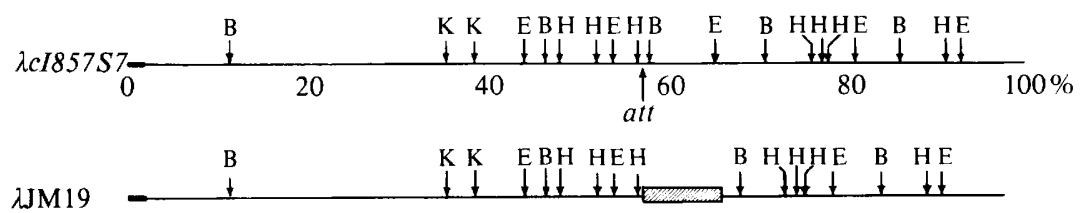

$\lambda \mathrm{JM} 20$

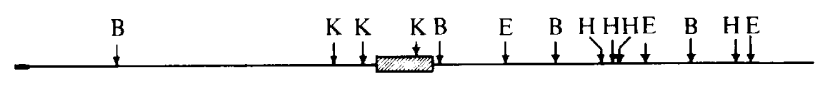

$\lambda \mathrm{JM} 23$

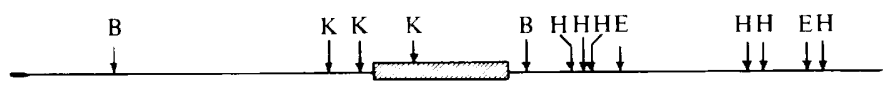

$\lambda \mathrm{JM} 24$

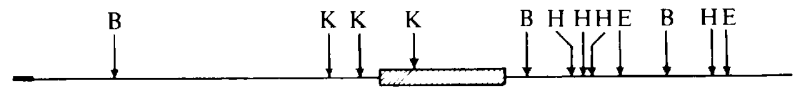

Fig. 3. Physical maps of $\lambda$ psrlA and its parental phages. EcoRI, HindIII, BamHI and KpnI restriction sites are indicated as $\mathrm{E}, \mathrm{H}, \mathrm{B}$ and $\mathrm{K}$, respectively. The $\lambda$ attachment site $($ att $)$ is indicated for $\lambda c 1857 S 7$ and the maps are aligned through this site. The $E$. coli DNA is indicated as hatched boxes.

and $\mathrm{srlC}^{+}$(the inducible allele) are dominant. This supports our previous model of negative control of the $s r l$ operon and contrasts with the views of Lengeler (1975) and McEntee (1977) who favour positive control models. Either the gene we refer to as $s r l C$ is not identical to their gutC, or we are examining a situation that is the converse of that described by Markowitz \& Rosenbaum (1965), who described a control system in which the exogenotic allele of a regulatory gene was always dominant.

Biochemical characterization. Restriction endonuclease analyses of the genomes of $\lambda$ wild-type ( $\lambda c I 857 S 7), \lambda \mathrm{JM} 19, \lambda \mathrm{JM} 20, \lambda \mathrm{JM} 23$ and $\lambda \mathrm{JM} 24$ were carried out using EcoRI, 
HindIII, BamHI and KpnI. The physical maps constructed are shown in Fig. 3. The positions of the cleavage sites in $\lambda$ wild-type are those described by Davies et al. (1980). As compared with $\lambda$ wild-type, the $B a m H I$ and $E c o$ RI restriction sites to the right of the $\lambda$ attachment site (att) are not present in $\lambda \mathrm{JM} 19$, thus indicating a replacement of $\lambda$ DNA by $E$. coli DNA at this position. Similarly, the loss in $\lambda \mathrm{JM} 20$ of the EcoRI, HindIII and BamHI restriction sites to the left of att indicates that the cloned DNA is replacing the $\lambda b$ region. The physical maps of $\lambda \mathrm{JM} 23$ and $\lambda \mathrm{JM} 24$, which carry the complete $s r l A^{+}$gene, are consistent with the joining of the two parts of the $s r l A$ gene carried by $\lambda \mathrm{JM} 19$ and $\lambda \mathrm{JM} 20$.

The DNA of $\lambda \mathrm{JM} 20, \lambda \mathrm{JM} 23$ and $\lambda \mathrm{JM} 24$ has an extra KpnI restriction site within the bacterial DNA inserted at the left of att. No EcoRI, HindIII or BamHI restriction site has been detected in the cloned $E$. coli DNA.

The sizes of $\lambda \mathrm{JM} 19, \lambda \mathrm{JM} 20, \lambda \mathrm{JM} 23$ and $\lambda \mathrm{JM} 24$ DNA calculated from the sizes of the restriction fragments are $47 \cdot 8,43 \cdot 8,47 \cdot 5$ and $42 \cdot 6$ kilobase-pairs, respectively.

\section{DISCUSSION}

We have described a method for the isolation of a specialized transducing phage for the gene $\operatorname{srlA}$, which specifies the membrane-bound Enzyme II of the phosphoenolpyruvatedependent phosphotransferase system (Kundig et al., 1964) that is specific for sorbitol. The rationale for the method was as follows (Fig. 1): (1) to integrate $\lambda$ into the $\operatorname{srlA}$ gene; (2) to isolate aberrantly excised $\lambda$ from this lysogen, selecting only on the basis of properties of the phages, not on the nature of the $E$. coli DNA carried by them; (3) to reconstitute the $s r l A^{+}$ gene from the two phages in a dilysogen; and (4) to isolate from the dilysogen a single phage carrying the intact $s r l A^{+}$gene.

As a technique the method has two advantages. First, the selection of the initial phages does not rely on the genetic information of the $E$. coli DNA acquired. Secondly, comparison of the restriction maps of the phages (Fig. 3) indicates the presence of restriction fragments, peculiar to $\lambda \mathrm{JM} 19$ and $\lambda \mathrm{JM} 20$, that carry the left and the right sides of the $\lambda$ att site, respectively. If the DNA of these fragments were sequenced, one would observe an unknown (E. coli) sequence attached to a known $(\lambda)$ sequence. From the method of construction of the phage, these points defined in the DNA sequence must lie within the gene defined by the original $\lambda$ insertion mutation, thus relating the two.

We do not as yet have a good estimate of the size of the $E$. coli DNA in our phages: the $E$. coli DNA in $\lambda \mathrm{JM} 24$ is between 3.4 and 9.1 kilobase-pairs. A more precise determination might be possible with a different restriction endonuclease, or alternatively by heteroduplex analysis.

The right-hand end of the DNA of $\lambda \mathrm{JM} 23$ is unlike that of $\lambda \mathrm{JM} 24, \lambda \mathrm{JM} 20$ or wild-type $\lambda$ (Fig. 3), yet both $\lambda \mathrm{JM} 23$ and $\lambda \mathrm{JM} 24$ were isolated from the same lysogen. $\lambda \mathrm{JM} 23$ cannot have arisen by recombination between a phage of $\lambda J M 24$ type and the phage 21 used in its isolation since the restriction map of phage 21 is quite different (data not shown). A more plausible explanation is that $\lambda \mathrm{JM} 23$ arose by recombination with a cryptic lambdoid prophage present in one of our strains, though this hypothesis would be difficult to test.

We thank Drs P. Oliver, R. S. Buxton, M. D. Yudkin and R. Lathe for gifts of strains, advice and encouragement. This work was supported by the Science Research Council through grant G/RA/22482 and was performed during the tenure by A.B. of an EMBO Long.Term Fellowship.

Dedicated to the memory of Mary Randle Lunt.

\section{REFERENCES}

Amaral, D. \& Kornberg, H. L. (1975). Regulation of fructose uptake by glucose in Escherichia coli. Journal of General Microbiology 90, 157-168.

BECKWITh, J. R., SIGNER, E. R. \& EPSTEIN, W. (1966).
Transposition of the lac region of E. coli. Cold Spring Harbor Symposia on Quantitative Biology 31, 393-401.

Buxton, R. S., Hammer-Jespersen, K. \& Hansen, 
T. D. (1978). Insertion of bacteriophage lambda into the deo operon of Escherichia coli $\mathrm{K} 12$ and isolation of plaque forming $\lambda \mathrm{deo}^{+}$transducing bacteriophages. Journal of Bacteriology 136, 668-681.

Davies, R. W., Botstein, D. \& Roth, J. R. (1980). Advanced Bacterial Genetics. Cold Spring Harbor: Cold Spring Harbor Laboratory.

Davis, M. G. \& Calvo, J. M. (1977). Isolation and characterization of $\lambda$ pleu bacteriophages. Journal of Bacteriology 129, 1078-1090.

Gottesman, M. E. \& Yarmolinsky, M. B. (1968a). Integration-negative mutants of bacteriophage lambda. Journal of Molecular Biology 31, 487-505.

GotTesman, M. E. \& YARMolinsky, M. B. (1968b). The integration and excision of the bacteriophage lambda genome. Cold Spring Harbor Symposia on Quantitative Biology 33, 735-747.

Henderson, P. J. F., Giddens, R. A. \& JonesMORTIMER, M. C. (1977). Transport of galactose, glucose and their molecular analogues by Escherichia coli K12. Biochemical Journal 162, 309-320.

JoNes-MorTIMER, M. C. \& KorNBERG, H. L. (1976). Uptake of fructose by the sorbitol phosphotransferase of Escherichia coli K12. Journal of General Microbiology 96, 383-391.

Kornberg, H. L., WATTS, P. D. \& Brown, K. (1980). Mechanisms of 'inducer exclusion' by glucose. FEBS Letters 117, Supplement, K28-K36.

Kundig, W., Ghosh, S. \& Roseman, S. (1964). Phosphate bound to histidine in a protein as an intermediate in a novel phosphotransferase system. Proceedings of the National Academy of Sciences of the United States of America 52, 1067-1074.

LENGELER, J. (1975). Mutations affecting transport of the hexitols D-mannitol, D-glucitol and galactitol in Escherichia coli $\mathrm{K} 12$ : isolation and mapping. Journal of Bacteriology 124, 26-38.

Lindahl, G., Sironi, G., Bialy, G. \& Calendar, R. (1970). Bacteriophage lambda: abortive infection of bacteria lysogenic for phage P2. Proceedings of the National Academy of Sciences of the United States of America 66, 587-594.
Markowitz, A. \& Rosenbaum, N. (1965). A regulator gene that is dominant on an episome and recessive on a chromosome. Proceedings of the National Academy of Sciences of the United States of America 54, 1084-1091.

Mata, M., Delstanche, M. \& Robert-Badouy, J. (1978). Isolation of specialised transducing bacteriophages carrying the structural genes of the hexuronate system in Escherichia coli K12: exu region. Journal of Bacteriology 133, 549-557.

MCENTEE, K. (1977). Genetic analysis of the Escherichia coli K12 srl region. Journal of Bacteriology 132, 904-911.

McGinnis, J. F. \& Paigen, K. (1969). Catabolite inhibition: a general phenomenon in the control of carbohydrate utilisation. Journal of Bacteriology 100, 902-913.

Morse, M. L., Lederberg, E. M. \& Lederberg, J. (1956). Transduction in Escherichia coli K12. Genetics 41, 142-156.

Mousset, S. \& Thomas, R. (1968). Dilysogenic excision: an accessory expression of the termination function? Cold Spring Harbor Symposia on Quantitative Biology 33, 749-754.

Press, R., Glansdorff, N., Miner, P., De Vries, J., KADNER, R. \& MAAS, W. K. (1971). Isolation of transducing particles of $\phi 80$ bacteriophage that carry different regions of the Escherichia coli genome. Proceedings of the National Academy of Sciences of the United States of America 68, $795-798$.

Roberton, A. M., Sullivan, P. A., JonesMortimer, M. C. \& KornberG, H. L. (1980). Two genes affecting glucarate utilization in Escherichia coli K12. Journal of General Microbiology 117, 377-382.

Shimada, K., Weisberg, R. A. \& Gottesman, M. E. (1972). Prophage $\lambda$ at unusual chromosomal locations. I. Location of the secondary attachment sites and properties of the lysogens. Journal of Molecular Biology 63, 483-503. 